\title{
OS DIREITOS HUMANOS E O PROBLEMA DO REFUGIADO NO MUNDO CONTEMPORÂNEO ${ }^{1}$
}

The Human Rights and the refugee issue in the current world

http://dx.doi.org/10.21116/2016.4

\section{BARSALINI, Glauco}

Pontifícia Universidade Católica de Campinas

\section{ALMEIDA, Patrícia Aparecida de \\ Pontifícia Universidade Católica de Campinas}

\begin{abstract}
Resumo: No caminho do que propõe o filósofo brasileiro Oswaldo Giacoia Junior, o presente artigo discute a problemática do refugiado no mundo contemporâneo utilizando-se, para tanto, do conceito de homo sacer desenvolvido pelo jusfilósofo hodierno Giorgio Agamben. Por sua pertinência ao tema invoca-se, aqui, formulações do jurista e cientista político Norberto Bobbio acerca dos direitos humanos, contribuições de Flávia Piovesan a respeito da legislação internacional relativa aos direitos humanos, bem como o conceito de biopolítica desenvolvido por Michel Foucault. Finalmente, a partir de documentos do ACNUR (Alto Comissariado das Nações Unidas para Refugiados) e à luz dos pensadores mencionados, realizase breve análise sobre a realidade de refugiados na atualidade.
\end{abstract}

Palavras-chave: direitos humanos; homo sacer; refugiado.

Abstract: In the way that is purposed by the Brazilian philosopher Oswaldo Giacoia Junior, the present article discuss the refugee's problematic in the current world using, for this, the homo sacer concept developed by the hodiernal philosopher Giorgio Agamben. By its pertinence to the theme, it is evoked formulations bu the jurist and politic scientist Norberto Bobbio about the Human Rights, contribution of Flávia Piovesan about the international legislation relative the Human Rights, as well as biopolitcs concepts developed by Michel Foucault. Finally, from the UNHCR documents (UN Refugee Agency), and from the light of the thinkers mentioned, it is done a brief analysis about the refugee reality today.

Key-Words: human rights, homo sacer, refugees.

"Ao longo de todo o tempo em que aqui estive, ansiei inconscientemente - e por vezes conscientemente - por confiança, amor e afeição fisica. Este anseio pode variar em intensidade, mas está sempre presente."

Anne Frank

\footnotetext{
1 O presente artigo, aqui parcialmente reformulado, foi apresentado no XX Encontro de Iniciação Científica da PUC-Campinas, 2015 (trabalho que ganhou publicação nos Anais do evento) sob o título "O homo sacer contemporâneo: do "muçulmano" ao refugiado."
} 


\section{Introdução}

O texto que se segue visa problematizar os direitos humanos e compreender melhor as implicações que envolvem o refugiado no mundo atual. Para tanto, dividese em duas etapas: primeiramente, apresenta reflexões conceituais sobre a temática e, em seguida, promove, à luz de tais formulações, discussão acerca de documentos de direito internacional atinentes aos direitos dos refugiados.

O artigo desenvolve certo diálogo entre Norberto Bobbio, Flávia Piovesan, Michel Foucault, Giorgio Agamben e Oswaldo Giacoia Junior. Ao trabalhar com os conceitos de biopolítica e de homo sacer, objetiva problematizar a estrutura estatal, entendendo que ela se funda sobre a violência, criando ambivalências. Compreende, pois, que a fundamentação e aplicação dos direitos humanos e, por conseguinte, dos direitos dos refugiados encerram, em si, um paradoxo: se por um lado defendem a dignidade àqueles que migram forçadamente de suas pátrias, por outro, são instrumentos para escamotear-se a efetiva emancipação dos indivíduos expostos.

Nessas bases metodológicas promove-se análise sobre documentos acerca dos refugiados, concluindo pelo caráter provisório de seus direitos.

\section{Os Direitos humanos, a biopolítica e a figura do homo sacer}

Norberto Bobbio (2004) inventaria a história dos direitos humanos, desde o surgimento das questões sobre fundamentação, estruturação e positivação de tais direitos. O autor se filia à corrente dos defensores dos direitos humanos e de que eles representam, de fato, um progresso da humanidade, algo "desejável" e que deve ser perseguido. Destaca o que para ele seria o problema real com o qual os juristas devem realmente se preocupar, a saber, a aplicação dos direitos humanos e aponta, também, a importância e a grande conquista nesse campo: a positivação de uma série de questões morais, constitutivas do Preâmbulo dos Direitos Humanos, conjunto de valores inestimáveis para história do mundo. Ressalta, ainda, que há um caminho a seguir a fim de que estas leis morais não se "cristalizem", e que o direito deve estar atento para a dinâmica social, de modo a acolher os novos conceitos e padrões morais que se estabelecem ou que se querem fixar, promovendo as devidas adaptações junto às transformações ocorridos nas sociedades bem como às demandas que nelas surgem. Aduz que as transformações sociais ocorridas na ISSN 1679-8902 
sociedade contemporânea impuseram grandes desafios para os direitos humanos e ressalta o caráter positivo da normatização dos direitos humanos. Concordando com a proposição de Kant, Bobbio defende que a humanidade estaria "destinada" rumo ao avanço moral:

Inspirando-me nessa extraordinária passagem de Kant, exponho a minha tese: do ponto de vista da filosofia da história, o atual debate sobre os direitos do homem - cada vez mais amplo, cada vez mais intenso, tão amplo que agora envolveu todos os povos da Terra, tão intenso que foi posto na ordem do dia pelas mais autorizadas assembleias internacionais - pode ser interpretado como um "sinal premonitório" (signum prognosticum) do progresso moral da humanidade. (BOBBIO, 2004, p. 49)

O jurista reconhece, contudo, que há muito a se fazer para que se chegue à perfeita conclusão deste avanço ao progresso moral, e que a humanidade está longe de seu pleno cumprimento. Entende, pois, que os direitos humanos se constituem como um "projeto" de longo prazo.

Em harmonia com Bobbio, a jurista Flávia Piovesan (2010) expõe os precedentes da internacionalização e universalização dos direitos humanos. Em sua abordagem elenca fatores importantes constitutivos da criação da Organização das Nações Unidas (ONU) em 1945 e, em sequência, da promulgação da Declaração Universal dos Direitos Humanos (1948), eventos que contribuíram para o início da solidificação dos direitos humanos no sistema do Direito Internacional. Nas palavras da autora: "Não mais poder-se-ia afirmar, no fim do século XX, que o Estado pode tratar de seus cidadãos da forma que quiser, não sofrendo qualquer responsabilização na arena internacional" (PIOVESAN, 2010, p. 123).

Piovesan aponta a centralidade das Nações Unidas para o processo de solidificação dos direitos humanos em escala internacional. Destaca que a Organização desempenhou papel fundamental na reconfiguração de um novo contexto das relações internacionais, que passaram a ser redefinidas segundo parâmetros estabelecidos por seu documento de fundação, a Carta das Nações Unidas (1945). Nela se assinalaram, a título universal e, portanto, como norteadores para toda a comunidade internacional, as principais preocupações e objetivos da defesa dos Direitos Humanos. Neste contexto, a Declaração Universal dos Direitos Humanos aflorou como proposta para uma "ética universal" composta, portanto, por princípios centrais que deveriam ser adotados por todos Estados do mundo, 
pautando-se, centralmente, na preservação da dignidade humana com a finalidade da promoção de direitos - mediante o amparo de leis - à todos os seres humanos. $A$ autora aduz que, no que se refere às indagações quanto ao valor jurídico da Declaração, uma série de nomenclaturas valorativas são descartadas: seu caráter internacional não inibe seu valor jurídico porque os países signatários assumem a obrigação de proteger os direitos humanos promovidos pela Declaração.

Em linha diversa à de Bobbio e à de Piovesan, Michel Foucault (2005) demonstra que, em complementação ao "velho direito de soberania" (o absolutismo), desde o século XVIII o Estado engendra uma nova forma de governar a partir do que a vida ganha relevância central. Inaugura-se a era da biopolítica e do biopoder. Enquanto no absolutismo a ordem era "fazer morrer e deixar viver", ou seja, o poder que se exercia sobre a vida humana era total no sentido de que o rei podia trucidar o seu súdito, na modernidade o soberano passa a "fazer viver e deixar morrer". Criase, então, uma nova técnica de intervenção política, cujas ferramentas atuam sobre a natalidade, a morbidade e as incapacidades biológicas diversas, o que permite maior controle sobre a sociedade. Aqui, o Estado possui informações, desde as mais gerais até as atinentes às minúcias da vida dos cidadãos a partir do que passa a direcionar a sua atuação, intervindo na forma de vida da população e mantendo, com isso, "o controle" sobre toda a sociedade e sobre cada um dos indivíduos, garantindo, sempre, o status de detentor do poder. Quanto às variáveis humanas sobre as quais atua:

São esses processos de natalidade, de mortalidade, de longevidade que, justamente na segunda metade do século XVIII, juntamente com uma porção de problemas econômicos e políticos (os quais não retomo agora), constituíram, acho eu, os primeiros objetos de saber e os primeiros alvos de controle dessa biopolítica. (FOUCAULT, 2005, p. 290)

Ao perscrutar sobre a origem do Estado moderno, o pensador francês problematiza a estrutura estatal, sua conduta e suas formas, chegando à conclusão de que, em sua gênese, o Estado possuiu este caráter violento e excludente. Nesse sentido o papel e posição da população neste cenário, segundo Foucault, é de que:

A população aparece, portanto, mais como fim e instrumento do governo que como força do soberano; a população aparece como sujeito de necessidades, de aspirações, mas também como objeto nas mãos do governo; como consciente, frente ao governo, daquilo 
que ela quer e inconsciente em relação àquilo que se quer que ela faça. (FOUCAULT, 2000, p. 375)

A biopolítica implica em que de um lado o Estado promove a vida e, de outro, ele escolhe quais vidas devem viver e quais podem morrer - e de que modo isso deve acontecer. O Estado é, portanto, na sua própria gênese, violento, violência essa que se funda no preconceito e no racismo. Foucault destaca:

Portanto, o racismo é ligado ao funcionamento de um Estado que é obrigado a utilizar a raça, a eliminação das raças e a purificação da raça para exercer seu poder soberano. A justaposição, ou melhor, o funcionamento, através do biopoder, do velho poder soberano do direito de morte implica o funcionamento, a introdução e a ativação do racismo. E é aí, creio eu, que efetivamente ele se enraíza. (FOUCAULT, 2005, p. 309)

No caminho de Michel Foucault, com o intuito de construir uma reflexão acerca da exclusão dos seres humanos, Giorgio Agamben (2004) avança, utilizando o termo romano homo sacer. Toma por empréstimo, nesse caso, específica conotação dada na antiguidade ao referido termo: a do homem destituído de todo e qualquer amparo a seu favor, aquele que pode ser morto sem que essa ação seja considerada crime, a vida nua. Aqui, Agamben retoma os conceitos gregos de zoé e bíos - o primeiro, referente à vida na dimensão biológica, no sentido da existência física, dos aspectos morfológicos que todos os seres humanos possuem e, o segundo, relativo à dimensão política, correspondendo à cidadania, à condição que confere direitos e deveres aos seres humanos. O homo sacer é aquele que está na fratura entre biós e zoé; é vida nua, povoa um reino que se inaugura no limiar dado entre a vida e a morte, uma fenda entre um lugar e outro. Ele é lançado ao lugar da não-vida e da não-morte e por isso é, pois, não propriamente um vivente, mas um sobrevivente.

Em O que resta de Auschwitz, Agamben identifica o homo sacer na figura do "muçulmano", presos que, no campo de concentração, sobreviviam à mais degradante das condições. Doentes e desnutridos, eram sobreviventes já incapazes de reagir à hostilidade, nem à raríssima gentileza ou a qualquer outro estímulo: eram como "mortos vivos". O "muçulmano" era desprezado até mesmo pelos demais prisioneiros como, também, pelos carrascos. Ao colocar em discussão a figura do homo sacer, identificando a sua existência, Agamben problematiza a estrutura que cria a vida nua. Acusa a consolidação, na contemporaneidade, do estado de 
exceção permanente, em que a biopolítica, como política calcada na violência, gera a separação radical entre incluídos e excluídos. Além do "muçulmano", existem outros exemplos de homo sacer, figuras criadas por uma estrutura estatal excludente e violenta, dentre as quais, o refugiado: aquele que acarreta estranhamento entre as condições de homem e cidadão, "figura inquietante", "conceito-limite" que ameaça a organização e a lógica do Estado que se ergue sobre os conceitos de soberania, nação e território. Nas palavras de Agamben (2015, p. 30), o refugiado "é considerado por aquilo que é, ou seja, nada menos do que um conceito-limite que põe em crise radical os princípios do Estado-nação e, ao mesmo tempo, permite liberar o campo para uma renovação categorial doravante inadiável. " É, pois,

[...] a única figura pensável do povo no nosso tempo e, ao menos até quando não for realizado o processo de dissolução do Estado-nação e da sua soberania, a única categoria na qual hoje é permitido entrever as formas e os limites de uma comunidade política por vir. (AGAMBEN, 2015, p. 24)

Em diálogo com as obras de Michel Foucault e de Giorgio Agamben, Oswaldo Giacoia Júnior problematiza a temática direitos humanos. Para tanto, recupera a discussão levantada por Karl Marx, em o 18ํㅜ Brumário de Napoleão Bonaparte, a respeito da diferenciação entre homem e cidadão. Marx observa que se apresentam dois termos distintos na Declaração Universal dos Direitos do Homem e do Cidadão: homem e cidadão. O homem é aquele que vive a condição da cidadania efetiva - é, pois, o burguês. Cidadão corresponde a uma ficção jurídica que, aplicável a todos os indivíduos, somente se realiza no burguês, nunca no proletariado. A respeito da "condição volátil e inexequível" dos direitos humanos, construídos no século XX, Giacoia aduz:

Ora, no século $X X$, em decorrência da configuração da sociedade burguesa como uma sociedade de massas, emergente da revolução industrial, esses direitos passam a evidenciar seu inegável condicionamento histórico, assim como sua condição volátil, mostrando-se inexeqüíveis precisamente em relação a seres humanos despossuídos de todos os atributos e qualidades diversos da mera e nua pertença ao gênero humano. Desprovidos de um estatuto político definido e, portanto, desprovidos da proteção das comunidades jurídicopolíticas nacionais, estavam também concretamente privados dos presumíveis direitos humanos universais. (GIACOIA, 2008, p. 6-7) 
A crítica acima se refere à aplicação de tais direitos. Na distância imposta entre burgueses e trabalhadores (Marx) ou na impossibilidade de que o trabalhador animal laborans - acesse algo mais do que a mera unidade produtiva (Hannah Arendt), constata-se que muitos e muitos sujeitos estão alijados da integralidade dos direitos do ser humano.

$\mathrm{Na}$ concepção de Foucault e de Agamben, o ponto principal se refere à "função histórica" dos direitos humanos diante do modelo biopolítico. Sobre isso, Giacoia discorre:

[...] ao lado da função emancipatória das declarações de direitos fundamentais, seria também indispensável perceber que elas integram o dispositivo de abandono da vida nua à violência dos mecanismos de poder. Ora, é nesse sentido que a arqueologia das sociedades européias modernas, configuradas como sociedades bio-políticas ao longo do século XVIII e depois, fornece um instrumental teórico indispensável para as análises de Agamben. (GIACOIA, 2008, p. 9)

que a arqueologia das sociedades modernas europeias realizada por Foucault demonstra é que a biopolítica se constitui como uma forma violenta de controle da vida humana fundada em certo "racismo político". Agamben, por sua vez, sugere que os direitos humanos não escapam de tal violência dado que, se por um lado constituem-se como "mecanismos de asseguramento dos direitos individuais e de liberdades públicas", por outro, compõe-se como instrumentos "de re-significação e investimento jurídico-político da vida no arcabouço institucional do Estado-nação" (GIACOIA, 2008, pp. 8 e 9). Aqui, Giacoia promove uma relação de proximidade entre os termos vida nua e vida sacra, afirmando: "A meu ver, é a sacralidade comum ao homo sacer e ao caráter sagrado dos direitos humanos fundamentais que institui uma insidiosa cumplicidade entre a vida nua e o poder (bio-político) do direito." (GIACOIA, 2008, p. 9). O filósofo brasileiro não nega os benefícios que os direitos humanos trouxeram ao longo da história, entretanto, aponta o "caráter bifronte" de tais direitos. Há, de um lado, os benefícios que eles trazem mas, de outro, deve-se notar que eles se atrelam ao caráter violento do poder soberano, do que resulta, necessariamente, a exclusão humana. Escreve:

Não se trata, insisto, de uma condenação maniqueísta das declarações de direitos, que marcam o surgimento do constitucionalismo moderno. Trata-se, antes, de reconhecer que, ao lado de seu papel efetivamente emancipatório, de 
defesa contra o arbítrio e o despotismo do Estado, é preciso notar o caráter bifrontal de todo evento político decisivo. Nesse sentido, as declarações de direitos são a outra face do racismo bio-político. (GIACOIA, 2008, p. 14)

\section{Os direitos dos refugiados}

À Declaração Universal dos Direitos Humanos sobrevieram, a partir de novas necessidades e demandas sociais, medidas de caráter jurídico como pronunciações e a criação de estatutos específicos, a exemplo do Estatuto dos Refugiados.

Acolhendo a associação do refugiado com o homo sacer, feita por Giorgio Agamben, assim como por Oswaldo Giacoia Júnior, analisaremos, em seguida, alguns dos documentos da ONU destinados aos refugiados, a saber, a Convenção Relativa ao Estatuto dos Refugiados (1951) e a Determinação do Estatuto do Refugiado (1977). A Convenção Relativa ao Estatuto dos Refugiados é um dos principais documentos quanto à promoção do refugiado, sendo basilar e referencial para os demais documentos produzidos. Ela contém desde a definição da condição de refugiado aos seus principais benefícios, proteções e garantias tais como o direito à liberdade, ao credo religioso, à documentação de identificação, ao trabalho, dentre outros. A Convenção e a Determinação do Estatuto do Refugiado não são, na sua inteireza, taxativas. Há, em tais documentos, dispositivos menos claros, que permitem diversas interpretações, o que dá margem a possibilidades de efetivação em maior ou em menor grau do que parece ser o seu espírito, ou a sua intenção: a proteção ao refugiado. Encontra-se, na Determinação do Estatuto do Refugiado, 28a . Sessão do Comitê Executivo, 1977:

(i) O funcionário competente (por exemplo, funcionário de imigração ou da polícia de fronteiras) a quem o requerente, pessoalmente, se dirige na fronteira ou no território de um Estado contratante, deverá ter instruções claras para lidar com casos que possam cair no âmbito de instrumentos internacionais relevantes. Deve ser-lhe exigido que actue de acordo com o princípio de non-refoulement e que submeta esses casos a uma autoridade superior. (ACNUR, 1977) 
O non-refoulement, princípio do direito internacional, é definido como a garantia de não devolução de uma pessoa ao local que the tenha apresentado risco. A essência desse princípio é tratada também pelo Art. 33 da Convenção:

Nenhum dos Estados Contratantes expulsará ou rechaçará, de maneira alguma, um refugiado para as fronteiras dos territórios em que a sua vida ou a sua liberdade seja ameaçada em virtude da sua raça, da sua religião, da sua nacionalidade, do grupo social a que pertence ou das suas opiniões políticas. (NAÇÕES UNIDAS, 1951, p. 16)

O fato de que os países signatários da Convenção não possam expulsar refugiados para fronteiras de territórios em que sua vida ou liberdade estejam sob ameaça por motivo racial, religioso, de nacionalidade, ético ou político não implica, todavia, que tais Estados tenham de aceitar, necessariamente, pedido de refúgio. $\mathrm{E}$ esse tipo de negação não é incomum. O Estatuto, como as pronunciações, têm, pois, caráter provisório. Não garantem o reconhecimento de direitos plenos de cidadania e nem tampouco de permanência àqueles que não podem retornar aos seus países, o que os coloca sob o sério risco de terem suas vidas ou liberdade ceifadas ou cerceadas. Nas palavras de Agamben (2015, p. 28), "[...] o estatuto do refugiado foi sempre considerado, mesmo ou no melhor dos casos, como uma condição provisória, que deve levar ou à naturalização ou à repatriação. Um estatuto estável do homem em si mesmo é inconcebível no direito do Estado-nação. "

Nesta linha de raciocínio, vale a citação do Estatuto: "Art. 7․ Ressalvadas as disposições mais favoráveis previstas por esta Convenção, um Estado Contratante concederá aos refugiados o regime que concede aos estrangeiros em geral. " (NAÇÕES UNIDAS, 1951, p. 5). Ao refugiado se nega, pois, a cidadania. Equipará-lo ao estrangeiro não significa equipará-lo ao cidadão. Nesse sentido, na estrutura da soberania contemporânea, refugiados e estrangeiros não são tão cidadãos quanto os naturais ao Estado em que se encontram. A eles se destina um regime próprio e nunca politicamente integral.

A nota de Protecção Internacional em Situações de Influxo em Larga Escala (1995) do ACNUR (Alto Comissariado das Nações Unidas para Refugiados) aborda, dentre as principais preocupações que o problema do refugiado pode causar a um país, acerca da necessidade de número significativo de pessoas (ou grupos de pessoas) obterem refúgio em um único país. No documento apresentam-se algumas 
das dificuldades práticas na aplicação do Estatuto como relatos que evidenciam a violação do regimento e, também, o empenho de Estados para inviabilizar a entrada de refugiados, o que reforça ainda mais a vulnerabilidade da condição das pessoas refugiadas. Tais apontamentos expõem irregularidades a serem combatidas, referindo-se às negligencias que são cometidas, em sua maioria, por parte dos Estados e indicando a importância de que esses Estados, pelo contrário, exerçam papel positivo como colaboradores, fornecendo ajuda e proteção aos que a eles pedem socorro.

A respeito da biopolítica, Michel Foucault se refere ao racismo como meio pelo qual é justificada a ação violenta do Estado. Seguindo essa linha, os trechos da nota do ACNUR relatam indícios e os riscos desse tipo de atuação na contemporaneidade:

A flagrante violação dos direitos humanos por vários Estados, ou entidades não estatais, que seguem políticas de limpeza étnica' em diferentes regiões, tem vindo a aumentar a pressão sobre a questão da protecção. (ACNUR, 1995, p. 2)

16. Em algumas situações, os refugiados e os requerentes de asilo foram vítimas de ataques racistas. (ACNUR, 1995, p.6)

Dentre os documentos direcionados aos refugiados nas diversas questões encontra-se, também, o que se destina ao caso das crianças (Crianças refugiadas, 1989) e aquele que cuida da questão das mulheres (As mulheres refugiadas e a proteção internacional, 1990), alarmando para a urgência das necessidades especificas desses "sub-grupos". Esse fato realça posições de maior inferioridade dentro do grande "grupo de refugiados", desvinculando-se ainda mais de uma concepção de humanidade. Mulheres e crianças, seja pelo preconceito, pelas necessidades não supridas ou, então, pela dependência, são lançadas à vida nua. Elas se tornam, pois, comparáveis ao "muçulmano" do campo de concentração de Auschwitz. Conforme trecho, respectivos à proteção de crianças refugiadas:

(e) Condenou a exposição das crianças refugiadas a violência física e outras violações aos seus direitos fundamentais, quer seja através de abusos sexuais, tráfico de crianças, actos de pirataria, ataques militares ou armados, recrutamento forçado, exploração política ou detenção arbitrária e apelou à acção nacional e internacional que impeçam tais violações e que apoiem as vítimas; 
(i) Sublinhou a situação especial das crianças não acompanhadas e crianças separadas dos seus pais, que se encontram ao cuidado de outras famílias, incluindo as suas necessidades no que se refere à determinação do seu estatuto, providências para apoio físico e emocional e esforços para encontrar vestígios dos pais ou familiares;(ACNUR, 1989)

Os documentos revelam a necessidade de se acentuar a atenção às categorias especificas - mulheres e crianças - denotando sua maior vulnerabilidade dentre os refugiados, Destaque-se o registro de "grande preocupação a frequente incidência de violações dos direitos das mulheres refugiadas e das suas necessidades específicas." (ACNUR, 1990)

Vários são os apontamentos reunidos nos documentos do ACNUR, a respeito de descumprimento e desamparo quanto aos termos de proteção do refugiado. Vale a citação:

As medidas restritivas impostas pelos Estados incluem barreiras físicas e jurídicas para impedir a entrada de refugiados ou a obtenção de asilo nos seus territórios; regressos forçados e maciços, bem como a inexistência de padrões de tratamento uniformizados a nível internacional, conduzem, por vezes, a que os refugiados caiam no esquecimento. (ACNUR, 1995, p. 3)

Ainda,

Ao mesmo tempo, embora continue a ser importante a codificação na lei dos princípios fundamentais, a mera adesão aos instrumentos relevantes tem-se mostrado insuficiente para garantir uma resposta consistente e generosa às necessidades dos refugiados. Persiste um conjunto de factores implícitos, políticos, económicos e sociais, que podem também influenciar a resposta dos Estados face a influxos de refugiados e que podem inspirar medidas que estejam em conflito com os direitos básicos dos refugiados e dos requerentes de asilo. (ACNUR, 1995, p. 5)

O que o Alto Comissariado das Nações Unidas para Refugiados acusa é que os mesmos Estados que aderem a direitos internacionais também, dicotomicamente, não os cumprem. Ao reforçar a importância da codificação dos princípios fundamentais, o ACNUR parece não perceber a lógica dos poderes soberanos: a de geração de um estado de exceção permanente que cria excluídos e, ao mesmo tempo, leis para incluí-los, nunca integralmente mas, ao contrário, sempre precariamente. Incluídos em tais circunstâncias são provisórios: podem ser excluídos a qualquer momento. São os refugiados, os homo sacer contemporâneos. 


\section{Considerações Finais}

Este artigo teve por finalidade explorar, ainda que de modo breve, a problemática do refugiado em face dos direitos humanos. Ao refletir sobre tais direitos, Norberto Bobbio conclui que eles significam, de fato, um avanço para o projeto civilizatório da humanidade. Na mesma linha, Flávia Piovesan destaca o progresso legal dos direitos humanos no âmbito internacional. Michel Foucault, Giorgio Agamben e Oswaldo Giacoia Junior, por seu turno, promovem forte crítica aos destinos dos direitos humanos - de modo explícito, em Agamben e em Giacoia Junior, à relação entre os mesmos direitos e o refugiado contemporâneo. Ante as "incompatibilidades" entre dispositivos legais e as ações dos Estados, pode-se perceber como a biopolítica opera na atualidade, excluindo sujeitos de seus direitos de nacionais ou de cidadãos e incluindo-os, ao mesmo tempo, nos direitos humanos - estes, de caráter universal mas, nem por isso, garantidores de efetiva cidadania àqueles que alcança.

No centro das tensões entre o real exercício do poder soberano próprio aos Estados-Nação e a perspectiva finalista dos direitos humanos aos quais muitos desses Estados se comprometem na condição de signatários, revela-se certa fragilidade dos mecanismos internacionais de proteção. Não é incomum constatarse, em vários casos, a atuação negativa de Estados formalmente comprometidos com a proteção universal dos seres humanos - e, portanto, com os princípios que regem a atuação do ACNUR -, no acolhimento efetivo de refugiados. Reserva-se aos refugiados tratamento meramente provisório, o que é mais patente, ainda, nos casos de diversidade religiosa e étnico-raciais, elementos que, em contraste com nacionalismos radicais, não raro, inspiram impedimentos por países contemporâneos, destacadamente parte das nações mais ricas do mundo, a pequenos grupos ou a grandes populações.

Este artigo procurou tornar clara a condição de vulnerabilidade a que a figura do refugiado está exposta. Excluído pela força do poder soberano estatal ele é, por outro lado, incluído pelos direitos humanos internacionais. Justamente por isso o refugiado contemporâneo é, conforme Agamben (2015), aquele que tem potência 
para motivar uma crise à lógica "atual", a qual se estabelece na tríplice Estadonação-território; é, pois, a chave para o aparecimento de uma nova dinâmica política.

\section{REFERÊNCIAS}

ACNUR. Crianças refugiadas. 1989. [online]. Disponível em:

<http://www.acnur.org/t3/portugues/recursos/documentos/?tx_danpdocumentdirs_pi2 $\% 5 B m o d e \% 5 D=1 \& t x \_d a n p d o c u m e n t d i r s \_p i 2 \% 5 B f o l d e r \% 5 D=169>$ Acesso em 15 de junho de 2015.

. Determinação do estatuto do refugiado. 1977. [online]. Disponível em:

<http://www.acnur.org/t3/portugues/recursos/documentos/?tx_danpdocumentdirs_pi2 $\% 5 B m o d e \% 5 D=1 \& t x \_d a n p d o c u m e n t d i r s \_p i 2 \% 5 B f o l d e r \% 5 D=169>$ Acesso em 14 de junho de 2015.

. Protecção Internacional em Situações de Influxo em Larga Escala. 1995.

[online]. Disponível em:

<http://www.acnur.org/t3/portugues/recursos/documentos/?tx_danpdocumentdirs_pi2 $\% 5 B m o d e \% 5 D=1 \& t x \_d a n p d o c u m e n t d i r s \_p i 2 \% 5 B f o l d e r \% 5 D=169>$ Acesso em 15 de junho de 2015.

As mulheres refugiadas e a proteção internacional. 1990. [online]. Disponível em:

<http://www.acnur.org/t3/portugues/recursos/documentos/?tx_danpdocumentdirs_pi2 $\% 5 B m o d e \% 5 D=1 \& t x \_d a n p d o c u m e n t d i r s \_p i 2 \% 5 B f o l d e r \% 5 D=169>$ Acesso em 15 de junho de 2015.

AGAMBEN, Giorgio. Homo Sacer: o poder soberano e a vida nua I. Belo Horizonte: UFMG, 2004.

. Meios sem fim: Notas sobre a política. Trad. Davi Pessoa Carneiro. Belo Horizonte: Autêntica Editora, 2015.

. O que resta de Auschwitz: o arquivo e a testemunha. Homo Sacer III. Trad. Selvino J. Assmann. São Paulo: Boitempo, 2008. 
BOBBIO, Norberto. A era dos direitos. Trad. Carlos Nelson Coutinho. Apresentação de Celso Lafer. Nova edição. Rio de Janeiro: Elsevier, 2004.

FOUCAULT, Michel. Em defesa da sociedade. Trad. Maria Ermantina Galvão. 4aa . ed. São Paulo: Martins Fontes, 2005.

. Microfísica do poder. 15ª. Ed. Graal - RJ, 2000.

GIACOIA JUNIOR, Oswaldo. Sobre direitos humanos na era da biopolítica. Kriterion: Revista de Filosofia. no. 118, vol. 49. Belo Horizonte, Dec. 2008.

http://dx.doi.org/10.1590/S0100-512X2008000200002. In:

http://www.scielo.br/scielo.php?pid=S0100-512X2008000200002\&script=sci_arttext NAÇÕES UNIDAS. Convenção relativa ao estatuto dos refugiados. 1951. [online]. Disponível em:

$<$ http://www.acnur.org/t3/portugues/recursos/documentos/?tx_danpdocumentdirs_pi2 $\% 5 \mathrm{Bmode} \% 5 \mathrm{D}=1 \& \mathrm{tx}$ _danpdocumentdirs_pi2\%5Bfolder\%5D=181\&tx_danpdocument dirs_pi2\%5Bsort\%5D=doctitle,sorting,uid> Acesso em 14 de junho de 2015.

PIOVESAN, Flávia. Direitos Humanos e o Direito Constitucional Internacional. 11. ed. rev. e atual. São Paulo: Saraiva, 2010.

\section{Agradecimentos:}

Nossos agradecimentos ao CNPq - pelo financiamento da bolsa de pesquisa à acadêmica Patrícia Aparecida de Almeida - e à Pontifícia Universidade Católica de Campinas, pelo apoio no desenvolvimento deste artigo. 


\section{Breve Currículo dos autores:}

\section{Glauco Barsalini}

Professor Pesquisador do Programa de Mestrado em Ciências da Religião, Professor da Faculdade de Ciências Sociais da Pontifícia Universidade Católica de Campinas (PUC-Campinas). Orientador da pesquisa de que se originou o presente artigo. E-mail: glaucob@puc-campinas.edu.br

\section{Patrícia Aparecida de Almeida}

Graduanda em Ciências Sociais pela Pontifícia Universidade Católica de Campinas. Pesquisa realizada a partir do Programa Institucional de Bolsas de Iniciação Científica (PIBIC). Instituição Financiadora: CNPq. E-mail: patricia.aa2@puccampinas.edu.br 